CORRECTION

Check for updates

\title{
Correction to: Titers of SARS CoV-2 antibodies in cord blood of neonates whose mothers contracted SARS CoV-2 (COVID-19) during pregnancy and in those whose mothers were vaccinated with mRNA to SARS CoV-2 during pregnancy
}

Lior Kashani-Ligumsky (D), Miriam Lopian, Ronnie Cohen, Hila Senderovich, Shelly Czeiger, Ariel Halperin, Adina Bar Chaim, Irit Kremer, Joseph B. Lessing, Eli Somekh and Ran Neiger

(c) The Author(s), under exclusive licence to Springer Nature America, Inc. 2021

Journal of Perinatology (2021) 41:2696; https://doi.org/10.1038/s41372-021-01272-7

Correction to: Journal of Perinatology https://doi.org/10.1038/ s41372-021-01216-1, published online 25 September 2021
In Table 1 for this article, one item was incorrect. The table should have appeared as shown below. The original article has been corrected.

Table 1. Demographic data.

\begin{tabular}{|c|c|c|c|c|}
\hline & Group $1(n=29)$ & Group $2(n=29)$ & Group $3(n=21)$ & $p$ value \\
\hline Mean maternal age (years) & 30.1 & 32.5 & 28.5 & $0.03^{\mathrm{a}}$ \\
\hline Mean parity & 3.3 & 5.2 & 2.7 & $<0.05^{\mathrm{a}}$ \\
\hline Mean gestational age at delivery (weeks) & 39.5 & 39.3 & 38.8 & 0.29 \\
\hline Number of pre-term delivery & 0 & 0 & 0 & $\mathrm{n} / \mathrm{a}$ \\
\hline Mode of delivery, NVD, No. (\%) & $24(82.8)$ & 26(89.7) & 18(85.7) & 0.86 \\
\hline Mean neonatal antibody titer $\mathrm{U} / \mathrm{ml}$ & 83.7 & 225.5 & $\mathrm{n} / \mathrm{a}$ & $<0.05^{\mathrm{a}}$ \\
\hline
\end{tabular}

